\title{
German technician's confession spurs check on suspect data
}

[MUNICH] Germany appears to be facing its second major scientific fraud scandal within a year. Following the admission by a technician at the Max Planck Institute for Plant Breeding in Cologne that she had fabricated data in at least one scientific paper, the possible systematic manipulation of important experimental results for more than six years is now being investigated.

Scientists at the institute who helped to expose the case are now repeating experiments described in more than 30 papers published in leading journals such as Nature, Science, EMBO Journal and Proceedings of the National Academy of Sciences. The publications date back to 1992 .

The repeat experiments, which began in mid-April and are expected to be completed by the middle of next month, form part of a formal investigation into the affair by the Max Planck Society (MPS). Experiments in at least half a dozen papers have already been proven to be non-reproducible using specially developed tests.

The investigation will also attempt to determine how much responsibility for the length of time that the suspect data went unchallenged should be shouldered by Jeff Schell, one of the institute's four directors and head of its department of plant genetics where the experiments were carried out.

The fraud became public in March (see Nature 392, 111; 1998). But scientists in the department had long been suspicious about the work of a technician, Inge Czaja, as others had been unable to repeat her success with a particular assay for the enzyme adenylyl cyclase on cultured plant cells.

The role of this enzyme in hormonal signalling in plants has been controversial in the field for many years. The most recent paper from Richard Walden's group in the department, published in Nature last December (390, 698-701; 1997), appeared to provide definitive evidence that the enzyme exists in plants, and is part of the signalling system of the hormone auxin which promotes cell growth. The institute says it now intends to retract the paper in its previous form.

Before the investigation began, Walden

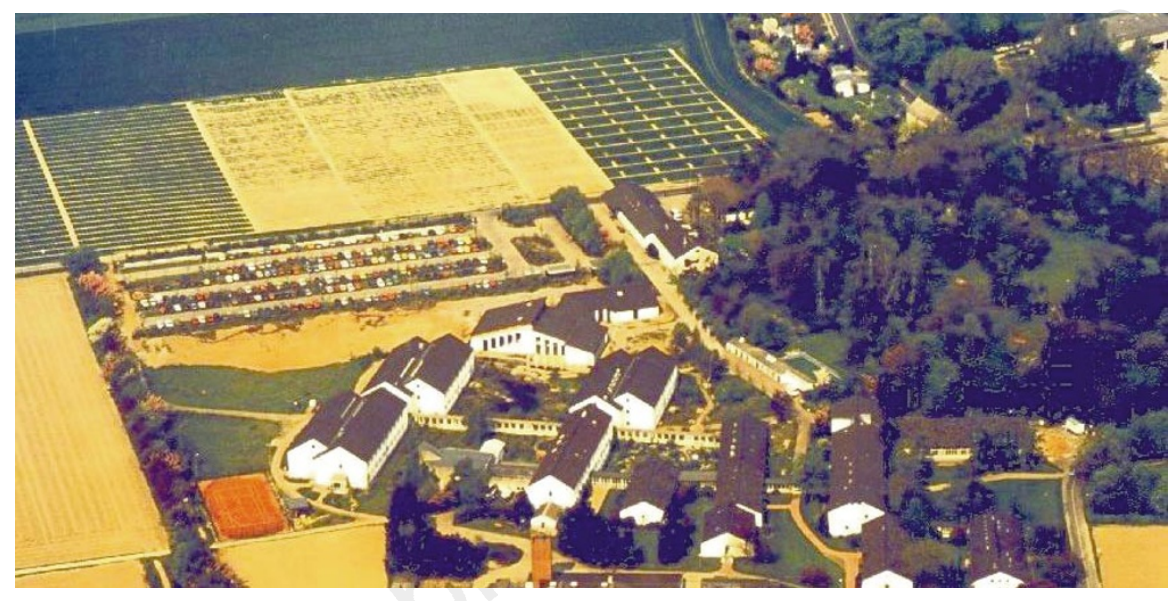

Weeding out misconduct: the Max Planck Institute for Plant Breeding is investigating some past results. had refused to allow blind tests to be done, as requested by other group leaders in the department, to validate suspicions that the assay was being manipulated.

The fraud was exposed when colleagues gave directly to the technician samples designed to establish whether or not the assay was being manipulated. Both Czaja and Walden left the institute in February. Walden claims no direct involvement in the fraud, but admits responsibility, as group leader, for the quality of work done by his group.

Franz Weinert, an MPS vice-president and director of the Institute for Psychological Research in Munich, is chairing the investigation. He says its first main aim is to clarify how many papers have been affected by the fraud, and to what extent.

The second aim is to determine, through discussions with the ten group leaders in the department, when suspicions were first voiced, and how Schell - co-author of some of the papers being investigated - reacted to concern expressed by group leaders. Weinert says the MPS is very concerned that fabrication of data appears to have continued for so many years without being exposed.

This is the first case to be dealt with under the MPS's new rules for handling scientific misconduct which were approved last year (see Nature 390, 430; 1997). Under these rules, an informal and confidential internal

\section{Mature wins publishing award}

The Periodical Publishers Association (PPA) last week named Nature as the International Magazine of the Year in the business and professional class.

The judges cited the "heightened awareness" Nature is attracting "throughout the world as the original source for significant scientific discoveries" and praised the new content and design introduced last year. The PPA awards are regarded as the most prestigious magazine industry awards in the UK. inquiry should be carried out within an institute when a suspicion is raised and completed within four weeks.

If grounds for suspicion are confirmed, the director must ask for a formal investigation by the society, to be carried out by a committee comprising a vice-president and three members of the MPS arbitration committee. This committee reports to the society's president, Hubert Markl, who will decide on sanctions.

In the current case, the process was initiated in the middle of April. "We are carrying out the investigation as fast as possible, while taking the time necessary to be as accurate as we can," says Weinert. The MPS will not "hush anything up", he says, and there will be "no taboos". He expects to report to Markl by the end of this month.

Last year the German scientific community was caught unprepared when two leading researchers in molecular medicine were accused of faking data over a period of at least five years in around 40 publications (see Nature 389, 105; 1997). In that case, too, a major concern was that the fraud had apparently been going on for a long time before exposure. Young researchers in the laboratory are said to have suspected that results were being fabricated, but were reluctant to voice suspicions outside their group.

Rules for handling such cases have now been introduced in many universities as well as in the MPS. These are designed to protect whistleblowers, as well as researchers who stand accused of misconduct.

Francesco Salamini, acting director of the Max Planck Institute of Plant Breeding, says that despite the depressed mood in Schell's department, "our scientists are doing all that can be done in such a dramatic case to find out the truth of what happened".

Alison Abbott 